Research Article

\title{
Investor Sentiment and Stock Price Crash Risk in the Chinese Stock Market
}

\author{
Binghui Wu $\mathbb{D}$, Yuanman Cai, and Mengjiao Zhang \\ International Business School, Shaanxi Normal University, Xi'an 710119, China \\ Correspondence should be addressed to Binghui Wu; vcmd@163.com
}

Received 8 October 2021; Accepted 23 November 2021; Published 10 December 2021

Academic Editor: Miaochao Chen

Copyright (C) 2021 Binghui Wu et al. This is an open access article distributed under the Creative Commons Attribution License, which permits unrestricted use, distribution, and reproduction in any medium, provided the original work is properly cited.

\begin{abstract}
This paper uses the partial least squares method to construct the investor sentiment index in Chinese stock market. The Shanghai Stock Exchange 180 Index and the Shenzhen Stock Exchange 100 Index are used as samples. From the perspectives of holistic sentiment and heterogeneous sentiment, this paper studies the impact of investor sentiment on stock price crash risk. The results show that investor sentiment can significantly affect stock price crash risk in Shanghai and Shenzhen A-share markets, especially in the Shenzhen A-share market no matter from which perspective. And investor pessimism has a greater impact on stock price crash risk in the Shenzhen A-share market from the perspective of heterogeneous sentiment. Compared with the available researches, this paper makes two contributions: (i) the comparative analysis is adopted to discuss the differences between Shanghai and Shenzhen A-share markets, abandoning the research approach that takes the two markets as a whole in existing literature, and (ii) this paper not only studies the impact of investor holistic sentiment on stock price crash risk from a macro perspective, but also adds a more micro heterogeneous sentiment and conducts a comparative analysis.
\end{abstract}

\section{Introduction}

In the early 1990s, China successively established Shanghai and Shenzhen A-share markets. However, due to the influence of low maturity, imperfect regulatory system, and irrational behavior of investors, the stock market showed a relatively complex characteristic of dynamic fluctuations. Since the latter half of 2015, the Chinese stock market has fluctuated sharply after a period of sustained rise in stock price. What ensued was sharp fluctuation phenomenon that about a thousand stocks rose by the daily limit and fell the next day. The abnormal fluctuation in stock market continued until the first half of 2016. Less than two years after the dramatic volatility, Chinese stock market triggered two consecutive circuit breakers in 2018. Generally speaking, the extent of the collapse is often bigger than the extent of the boom when stock prices fluctuate dramatically, which means that the phenomenon of stock price crash is more obvious than the phenomenon of stock market boom. The stock price crash can cause serious social and economic problems, which can not only reduce investors' wealth and investment enthusiasm greatly, but also hinder the healthy development of the capital market.

With the development of behavioral finance, investor sentiment is often used to explain the stock market anomalies. And then the influence of investors' behavior on the stock market can be studied from the perspective of human emotion. When the stock market performs well, investors tend to ignore the intrinsic value of stocks and excessively chase price growth. As a result, the stock price seriously deviates from its intrinsic value. Once the stock prices gradually return to their intrinsic value, investors' income will drop sharply in a short term. At that time, the pessimism of irrational investors spreads rapidly in the stock market, which causes the competitive selling of stocks and finally the rising risk of stock price crash. When investors are optimistic or pessimistic, their reaction to market news is also asymmetric. Therefore, it is necessary to study the impact of investor sentiment on stock price crash risk from holistic and heterogeneous perspectives, respectively.

Considering the differences between Shanghai and Shenzhen stock exchanges in issuance system, information 
disclosure system, and listed enterprise size, the impact of investor sentiment on stock price crash risk may be different. Therefore, taking the Shanghai Stock Exchange 180 Index and the Shenzhen Stock Exchange 100 Index as samples, this paper comparatively analyzes the impact of investor sentiment on stock price crash risk in Shanghai and Shenzhen A-share markets.

The contribution of this paper mainly lies in the comparative analysis of Shanghai and Shenzhen A-share markets and the empirical study of investor heterogeneity. Firstly, in the selection of research objects, the paper fully considers the differences between Shanghai and Shenzhen A-share markets and makes a comparative analysis of them. At present, most of the existing studies took the Chinese stock market as a whole or chose a single company's stock as the research sample, ignoring the differences between Shanghai and Shenzhen A-share markets. Due to the obvious differences between Shanghai and Shenzhen A-share markets in many aspects such as the listing system and the scale of listed companies, it is inappropriate to analyze them as a whole. Based on these two markets, the article analyzes the differences in the impact of investor sentiment on stock price crash risk. Secondly, in the selection of sentiment variables, this article studies the correlation between investor heterogeneous sentiment and stock price crash risk from a micro perspective. The existing studies on the correlation between investor sentiment and stock price crash risk are mostly carried out from a macro perspective. From the perspective of investor sentiment heterogeneity, this paper designs the dummy variables of investor optimism and pessimism and discusses the impact of investor heterogeneity on stock price crash risk in Shanghai and Shenzhen A-share markets. In a word, this article studies the impact of investor sentiment on stock price crash risk in Shanghai and Shenzhen A-share markets from the perspectives of holistic sentiment and heterogeneous sentiment and then compares and analyzes the empirical results of these two markets to further improve existing research.

The remainder is organized as follows. Section 2 shows the literature review from two aspects: the basic theory and metrics. Section 3 is the study design, including sample selection and index selection. Based on the index construction, investor sentiment index, stock price crash risk index, and control variable index are used for empirical analysis in Section 4. Finally, the conclusions are drawn in Section 5.

\section{Literature Review}

2.1. The Research of Basic Theory. Firstly, the research of basic theory focuses on the stock price crash risk. Stock price crash is generally defined as a cumulative price decline of more than $20 \%$ in a day, while stock price crash risk is expressed as the risk of a sharp drop in a short time. Blanchard and Watson firstly studied the formation mechanism of stock price crash from the perspective of behavioral finance, and they believed that the excessive optimism of irrational investors was the cause of the stock market bubble [1]. Hong and Stein put forward the analytical framework of investor heterogeneous beliefs further [2]. They believed that pessimistic investors did not participate in market transactions initially so that their bearish pessimism on stock prices could not be disclosed in the short-term market environment. However, when such pessimism is suddenly unleashed, it will immediately increase stock price crash risk. Due to the great differences among investors in Chinese stock market, diversified market emotions are easy to be produced and cause sharp fluctuations in the stock market. If the large diversity in market sentiment increases, the belief difference between individual and collective investors will be more obvious, and investor sentiment will probably cause stock price crash in this situation [3].

Although many factors can cause stock price crash, the existing researches can mainly be divided into three types from the perspective of investors in the stock market. The first type is the research of stock price crash risk from the perspective of the investor heterogeneous belief. Chen and Zhang used heterogeneous belief model and found that the investor heterogeneous belief was positively correlated with stock price crash risk under the market policy of banning short selling [4]. Xiong further confirmed that the investor heterogeneous belief was an important reason for the increase of stock price crash risk [5]. The second type is the research of stock price crash risk from the perspective of investor preference. Franke and Luders used the rational expectation model of intertemporal asset pricing and found the greater the heterogeneity of investor preference, the greater the fluctuation of stock prices and stock price crash risk [6]. In addition, investor preference for gambling stocks and auspicious numbers could also significantly affect stock price crash risk and expected return rate [7]. The third type is the research of stock price crash risk from the perspective of the institutional investor. Gao et al. pointed out that the increased shareholding ratio of institutional investors significantly inhibited stock price crash risk [8]. The reason was that the institutional investor held too many shares and could play an important role in financial stability. Dong et al. found that the increased shareholding ratio of institutional investors would aggravate stock price crash risk [9]. When the market efficiency was high, there was a negative correlation between the institutional investor's shareholding and stock price crash risk.

Secondly, the research of basic theory focuses on the relationship between investor sentiment and stock price crash risk. Based on the expectation of future cash flow and investment risk, investors gradually formed investment beliefs which could reflect their speculative tendencies. Due to their different investment beliefs and subjective judgments, investors eventually produced different individual views, which could be recognized as investor sentiment in the stock market. Shiller firstly found a certain correlation between investor sentiment and stock price crash, but he could not confirm whether the change of negative sentiment could cause stock price crash [10]. With the development of investor sentiment theory, the DSSW model proposed by De Long et al. confirmed that the panic sentiment of investors was the main cause of stock price crash [11]. Sun and Xiao used the posting data of the stock bar of Chinese A-share 
listed companies to measure investor sentiment [12]. The study showed that investor optimism could spread in the stock bar and increase stock price crash risk. Shen and Chen found that the upsurge of investor sentiment could aggravate stock price crash risk, and the panic and pessimism of investors had a significant impact on stock price crash risk for pledged stocks [13]. Smales chose the volatility index (VIX) as the measure of investor sentiment [14]. The research showed that investor pessimism had a significant impact on the stock returns across firm size and value, and also across industry. In addition, investor sentiment had a greater impact on stock returns during an economic recession or when market sentiment is at its lowest. Schmeling found that the individual investor sentiment based on consumer confidence had a negative correlation with stock market returns on average across countries [15]. Meanwhile, for countries that had poor stock market integrity and were more prone to herd-like behavior and overreaction, the negative correlation between investor sentiment and stock returns was more significant.

In addition, some scholars studied the reasons for high investor sentiment causing stock price crash risk. Li et al. studied the influence of investor sentiment on stock price crash risk from market level and enterprise level [16]. It is found that the fluctuation of investor sentiment could significantly increase stock price synchronization and thus aggravate stock price crash risk. However, the fluctuation of investor sentiment had no obvious effect on stock price synchronization. Li constructed a market manipulation model to analyze the effect of market manipulation on investor sentiment and stock price crash risk [17]. Besides, Ge et al. selected more than 280,000 micro blog messages of 34 companies during the stock price crash in China and then built the framework of "Emotion-Cognition-Market" [18]. The results showed that the social media could promote the change of investor cognition, and stock price crash risk would increase under the influence of investor panic.

2.2. The Research of Metrics. Firstly, investor sentiment can be measured through direct index, indirect index, and sentiment index based on Internet big data according to the existing literature.

The direct index reflects the change of investor sentiment by conducting a direct survey of investor market expectations through issuing questionnaires. In the early days, the representative direct indexes mainly included the American Association of Individual Investors Coefficient [19], Investors Intelligence Bearish Sentiment Index [20], Market Condition Index [21], and Consumer Confidence Index [22]. However, it was easy for investors to hide part of their real emotions in the questionnaire, which could lead to unreliable data and affected the accuracy of empirical results. Therefore, scholars began to use the real transaction data published in the market to measure investor sentiment, such as turnover rate in stock markets [23], IPOs first-day earning [24], and discount premium rate of closed-end funds [25]. Those three indexes were called indirect indexes. In the information era, researchers gradually turned to the mining of Internet big data and the application of crawler technology. For example, the phrases reflecting investor sentiment were obtained from social media and then analyzed again to construct an investor sentiment index [26]. This type of index innovated the method of measuring investor sentiment and improved the accuracy of the metrics and the ability of investor sentiment to predict stock market returns.

Considering that the single investor sentiment index was not representative enough, Baker and Wurgler used principal component analysis to extract the common part of proxy variables of multiple sentiments and construct the BW sentiment index [27]. This approach was widely adopted in many studies. Yi and Mao removed the influence of economic fundamentals and improved the BW sentiment index, which was called CICSI index [28]. It was concluded that the CICSI index could better measure investor sentiment in the Chinese stock market. Later, Xu and Zhou used the partial least squares (PLS) method to construct a weekly frequency sentiment index, and they found that investor sentiment could significantly predict the returns of different portfolios in Chinese stock market [29].

Secondly, stock price crash risk can be measured by negative return skewness coefficient of return rate, fluctuation difference of stock price, and dummy variable of stock price crash frequency. Chen firstly used the negative skewness coefficient of return rate and the fluctuation difference of stock price to measure stock price crash risk [30]. This research method laid a foundation for the subsequent research on stock price crash risk. For example, $\mathrm{Xu}$ et al. added the forward and lag terms of market returns to the above indexes to eliminate the influence of market fluctuations. They studied the stock price crash risk affected by listed companies' own factors and discussed the synchronization problem of stock prices [31]. Liu and Di used the negative skewness coefficient of return rate and the fluctuation difference of stock price to measure stock price crash risk and analyzed the relationship between heterogeneous institutional investors' shareholdings and the stock price crash risk of nonfinancial companies [32].

Since the negative return skewness coefficient of return rate and the fluctuation difference of stock price could only be used to measure stock price crash risk, it was unable to measure the occurrence of stock price crash accurately. Hutton et al. used the frequency of stock price crash to measure stock price crash [33]. As the variable was a dummy variable, it was supposed to be assigned according to the occurrence of stock price crash. When the stock price crash occurred, the value equaled 1 , while the value equaled 0 when the stock price crash did not occur. In addition, the stock price crash frequency took the difference of 3.09 times between the mean weekly return rate of a stock and its standard deviation value as the critical value. If the weekly return rate of stock was less than or equal to the critical value, the stock price was considered to be crashed this year. Shi and Yang used the negative skewness coefficient of weekly return rate and the fluctuation difference of stock price in different phases to measure stock crash risk in the process of studying the impact of tangible and intangible information on stock price crash risk [34]. 


\section{Study Design}

3.1. Sample Selection. The Shanghai Stock Exchange and the Shenzhen Stock Exchange are the two main stock exchanges in the Chinese mainland. Shanghai Stock Exchange was established on November 26, 1990, while Shenzhen Stock Exchange was established on December 1, 1990. The main difference between them lies in the types and sizes of listed companies. For the types of listed companies, the Shanghai Stock Exchange focuses on large and medium-sized state-owned enterprises, while the Shenzhen Stock Exchange focuses on small and medium-sized enterprises. In terms of the sizes of listed companies, the Shanghai Stock Exchange only has a Mainboard market, on which most of the listed companies are large firms. Also, the number of newly listed enterprises is relatively small. The Shenzhen Stock Exchange has the Mainboard market, the SME (Small and Medium Enterprise) board market, and the GEM (Growth Enterprise Market), on which most of the listed companies are small firms, and the number of newly listed enterprises is large as well. In China, companies are not allowed to be listed on both exchanges at the same time. Thus, this paper takes Shanghai and Shenzhen A-share markets as research objects and selects Shanghai Stock Exchange 180 Index and Shenzhen Stock Exchange 100 Index as stock samples, respectively. The Shanghai Stock Exchange 180 Index is composed of 180 stocks with the largest size and the best liquidity in the Shanghai A-share market. It is the most representative large-sized blue-chip stock index and can accurately reflect the changes in stock prices in the Shanghai A-share market. The Shenzhen Stock Exchange 100 Index contains 100 components with the largest circulating market value and the most active transactions in the Shenzhen A-share market, representing the core high-quality assets of Shenzhen A-share market. In order to make the research results more accurate, the following samples are excluded in this paper: (1) shares of financial companies; (2) special treatment shares, the shares of listed companies which are in abnormal financial conditions in Shanghai and Shenzhen A-share markets; (3) suspended shares; (4) shares with missing data; and (5) shares with fewer than 30 trading weeks in one year, considering the regression correctness of extended exponential model in the calculation of stock price crash risk.

As investors have different investment beliefs, they have different judgments on the future trend of the stock market and then show heterogeneous sentiment, such as optimism and pessimism. The paper divides investor sentiment into holistic sentiment and heterogeneous sentiment. The holistic sentiment is used to express the intensity of investor sentiment in the stock market, which can also be considered as the size of overall investor sentiment. The heterogeneous sentiment is used to express the degree of the antithesis between optimism and pessimism among investors. Proxy variables of investor sentiment index (monthly discount premium rate of closed-end funds, IPOs number, IPOs firstday earning, market turnover rate, number of new investor accounts, and consumer confidence index), macroeconomic climate index, control variable, and CSI 300 index in China are all from CSMAR database. The weekly return rate of individual stocks and the weekly return rate of the market are derived from the RESSET database. Taking into full consideration the availability of data and the nontradable shares reform period in China, the sample interval is selected from January 2007 to December 2017.

\subsection{Index Selection}

3.2.1. Investor Sentiment Index. In the construction of investor sentiment index, the principal component analysis method (PCA) may cause undetectable noises when selecting principal components. However, the PLS method can remove these noises well and improve the effectiveness of investor sentiment measurement. Therefore, this paper uses the PLS method to construct the monthly investor sentiment index at first and then takes its average value as the annual investor sentiment index in Chinese stock market. In the following process, the CSI 300 index is taken as the response variable, and the proxy variable of investor sentiment is taken as the independent variable. The PLS analysis is carried out twice through SPSSAU software.

Considering the availability of data, the paper chooses six proxy variables of investor sentiment, including monthly discount premium rate of closed-end funds (Fund), number of IPOs (Nipo), IPOs first-day earning (Ripo), market turnover rate (Turn), logarithm value of the number of new investor accounts opened (Acc), and consumer confidence index (Cci). Since there is time-advance or time-lag influence of different proxy variables on investor sentiment, this paper chooses the data of the six proxy variables above in the current phase and previous phase to form an initial index matrix composed of 12 proxy variables [27]. To eliminate the influence of macroeconomic factors, these 12 proxy variables are, respectively, regressed to the macroeconomic climate index, and the residuals are taken as the new proxy variable. The correlation coefficient matrix of proxy variables shows that many variables are highly correlated, with the maximal correlation coefficient reaching 0.939 . Therefore, this paper conducts the first PLS analysis after standardizing these 12 proxy variables. At the same time, the first three principal components are selected to combine with the root mean square error of prediction (RMSEP) and variable importance in the projection (VIP). The preliminary investor sentiment index $\left(S_{t}^{\mathrm{PLS} 1}\right)$ is obtained and shown in the following expression:

$$
\begin{aligned}
S_{t}^{\text {PLS1 }}= & -0.078 \text { Fund }_{t}-0.070 \text { Fund }_{t-1}+0.081 \mathrm{Nipo}_{t}+0.091 \mathrm{Nipo}_{t-1}+0.072 \mathrm{Ripo}_{t} \\
& -0.021 \mathrm{Ripo}_{t-1}+0.243 \mathrm{Turn}_{t}+0.283 \mathrm{Turn}_{t-1}+0.247 \mathrm{Acc}_{t} \\
& +0.214 \mathrm{Acc}_{t-1}+0.084 \mathrm{Cci}_{t}+0.120 \mathrm{Cci}_{t-1} .
\end{aligned}
$$


Through the correlation analysis of the preliminary investor sentiment index and the new proxy variable, the 12 correlation coefficients are obtained in sequence and shown in Table 1.

Comparing the size and significance of the correlation coefficient in Table 1, this paper finally constructs investor sentiment in Chinese stock market based on Fund ${ }_{t-1}, \mathrm{Nipo}_{t-1}$, $\mathrm{Ripo}_{t}, \mathrm{Acc}_{t-1}$, and $\mathrm{Cci}_{t-1}$. Then, according to the previous analysis steps, the five proxy variables are standardized in turn, and we conduct the PLS analysis again. Finally, the first two principal components are selected in combination with RMSEP and VIP, and the final investor sentiment index $S_{t}^{\text {PLS2 }}$ is obtained and shown in the following expression:

$$
\begin{aligned}
S_{t}^{\text {PLS2 }}= & 0.382 \text { Fund }_{t-1}+0.376 \mathrm{Nipo}_{t-1} \\
& -0.153 \mathrm{Ripo}_{t}-0.209 \mathrm{Acc}_{t-1}+0.257 \mathrm{Cci}_{t-1} .
\end{aligned}
$$

At $1 \%$ significant level, the correlation coefficient between $S_{t}^{\text {PLS1 }}$ and $S_{t}^{\text {PLS2 }}$ is 0.878 , which indicates that the investor sentiment index constructed by the 5 proxy variables above can better measure the investor sentiment.

In expression (2), the investor sentiment index in Chinese stock market is positively correlated with discount premium rate of closed-end funds last month, number of IPOs last month, and consumer confidence index last month, while it is negatively correlated with IPOs first-day earning this month and number of new investor accounts opened last month. Besides, the change of investor sentiment can be reflected in advance by monthly discount premium rate of closed-end funds, number of IPOs, consumer confidence index, and number of new investor accounts opened. When the discount premium rate of closed-end funds (or the number of IPOs last month) is bigger this month, the investor sentiment will be higher the next month, indicating that the investors are optimistic about the valuation of new shares. When the consumer confidence index is higher this month, the investor sentiment will be higher the next month. In this case, investors are willing to spend and invest more, and they are optimistic about the future of the stock market. But when the number of new investor accounts opened increases this month, the investor sentiment will become depressed the next month. It indicates that a large number of irrational investors are in the stock market. They tend to open accounts for short-term profits when new shares are issued. After a month, the investor enthusiasm dissipates, and investment sentiment drops. The negative correlation between IPOs first-day earning and investor sentiment index further verifies this point. As a large number of short-term investors leave the stock market after obtaining short-term gains, investment sentiment is depressed.

3.2.2. Stock Price Crash Risk Index. Based on the data of weekly return rates of individual stocks after market adjustment, the negative skewness coefficient of weekly return rate (Skew) and the fluctuation difference of stock price in different phases (Duvol) are calculated to measure stock price crash risk. Specifically, the residual in expression (3) is used for analyzing the stock price crash risk of listed companies.

$$
\begin{aligned}
r_{i, t, \tau}= & \alpha+\beta_{1} r_{m, t, \tau-2}+\beta_{2} r_{m, t, \tau-1}+\beta_{3} r_{m, t, \tau}+\beta_{4} r_{m, t, \tau+1} \\
& +\beta_{5} r_{m, t, \tau+2}+\varepsilon_{i, t, \tau} .
\end{aligned}
$$

Some variables need to be further elucidated in expression (3). $r_{i, t, \tau}$ is the return rate of $i$-th stock considering reinvesting dividends in $\tau$-th week of $t$-th year. $r_{m, t, \tau}$ is the market-weighted return of all stocks in $\tau$-th week of $t$-th year. Besides, two forward terms and two lag terms of $r_{m, t, \tau}$ are added to expression (3) to reduce the effect of stock price synchronicity [27]. The residual $\varepsilon_{i, t, \tau}$ is used to measure the market-adjusted return rate of $i$-th stock in $\tau$-th week of $t$-th year and represents the portion of $i$-th stock returns unexplained by the market.

Since the residual term distribution obtained after regression of expression (3) is biased, this paper performs a logarithmic transformation on the residual term to make it obey the standard normal distribution and defines the weekly return rate $\left(W_{i, t, \tau}\right)$ as:

$$
W_{i, t, \tau}=\ln \left(1+\varepsilon_{i, t, \tau}\right) .
$$

Based on $W_{i, t, \tau}$, the negative skewness coefficient of weekly return rate is expressed as Skew ${ }_{i, t}$ in expression (5) and the fluctuation difference of stock price in different phases is represented as Duvol $i, t$ in expression (6). Because the managers of the enterprise may hide negative news for their own interests, the rise of the weekly return rate of the stock is greater than the decline, and its distribution is asymmetrical. When the negative news is disclosed in a concentrated manner, the weekly return rate of the stock tends to fall, increasing stock price crash risk. Therefore, $\mathrm{Skew}_{i, t}$ and Duvol $_{i, t}$ are suitable for measuring stock price crash risk.

$$
\begin{aligned}
\operatorname{Skew}_{i, t} & =-\frac{\left[n(n-1)^{3 / 2} \sum W_{i, t, \tau}^{3}\right]}{\left[(n-1)(n-2)\left(\sum W_{i, t, \tau}^{2}\right)^{3 / 2}\right]}, \\
\operatorname{Duvol}_{i, t} & =\ln \left(\frac{\left[\left(n_{u}-1\right) \sum_{\text {down }} W_{i, t, \tau}^{2}\right]}{\left[\left(n_{d}-1\right) \sum_{\text {up }} W_{i, t, \tau}^{2}\right]}\right) .
\end{aligned}
$$

In expression (5), $n$ represents the number of trading weeks for $i$-th stock in one year. The larger the value of Skew $_{i, t}$ is, the more serious the return rate deviates from the normal distribution. That is, stock price crash risk increases. In expression (6), the calculation process of Duvol $_{i, t}$ is divided into the following three steps. Firstly, it needs to identify the rising and falling stages of the stock price. The weekly return rate can be written as $\bar{W}_{i, t}$. When $W_{i, t, \tau}$ is greater than $\bar{W}_{i, t}$, the stock price is in the rising stages. Conversely, when $W_{i, t, \tau}$ is less than $\bar{W}_{i, t}$, the stock price is in the falling stages. $n_{u}$ and $n_{d}$, respectively, represent the number of weeks in the rising stage and falling stage of $i$-th stock in the $t$-th year. Secondly, the standard deviation of the weekly return rate is, respectively, calculated in the rising and falling stages of the stock price and obtains the rising 
TABLE 1: The correlation coefficients between the preliminary investor sentiment index and the new proxy variable.

\begin{tabular}{|c|c|c|c|c|c|c|}
\hline $\begin{array}{l}\text { New proxy variable } \\
\text { Correlation coefficient }\end{array}$ & $\begin{array}{c}\text { Fund }_{t} \\
0.4346^{* * *}\end{array}$ & $\begin{array}{c}\mathrm{Nipo}_{\mathrm{t}} \\
0.8887^{* * *}\end{array}$ & $\begin{array}{c}\mathrm{Ripo}_{t} \\
0.2122^{* *}\end{array}$ & $\begin{array}{c}\text { Turn }_{t} \\
0.0020\end{array}$ & $\begin{array}{c}\mathrm{Acc}_{t} \\
0.3531^{* * *}\end{array}$ & $\begin{array}{c}\mathrm{Cci}_{t} \\
0.7486^{* * *}\end{array}$ \\
\hline New proxy variable & Fund $_{t-1}$ & $\mathrm{Nipo}_{t-1}$ & $\mathrm{Ripo}_{t-1}$ & $\operatorname{Turn}_{t-1}$ & $\mathrm{Acc}_{t-1}$ & $\mathrm{Cci}_{t-1}$ \\
\hline Correlation coefficient & $0.4349^{* * *}$ & $0.8921^{* * *}$ & 0.1001 & 0.0033 & $0.3595^{* * *}$ & $0.7568^{* * *}$ \\
\hline
\end{tabular}

Note. ${ }^{* * *},{ }^{* *}$, and ${ }^{*}$ indicate significant levels at $1 \%, 5 \%$, and $10 \%$, respectively.

fluctuation ratio and falling fluctuation ratio of the stock price. Thirdly, Duvol $i, t$ is calculated by taking natural logarithm to the ratio of the falling fluctuation level to the rising fluctuation level. The larger the value of Duvol $_{i, t}$ is, the more serious the return rate deviates from the normal distribution. It shows the greater stock price crash risk.

3.2.3. Control Variable Index. By referring to the research methods of mainstream literature $[16,27,35]$, the following control variables are added to study the impact of investor sentiment on stock price crash risk, including the annual average weekly return rate $\left(\right.$ Ret $\left._{t}\right)$, the annual standard deviation of weekly return rate $\left(\right.$ Sigma $\left._{t}\right)$, the logarithm of the enterprise's total assets $\left(\mathrm{Size}_{t}\right)$, the price-to-book ratio of the enterprise $\left(P b_{t}\right)$, the asset-liability ratio of the enterprise $\left(\operatorname{Lev}_{t}\right)$, and the total asset return rate $\left(\mathrm{Roa}_{t}\right)$ of the enterprise. At the same time, in order to study the impact of investor heterogeneous sentiment on stock price crash risk, this paper also introduces the dummy variable $\left(D_{t}\right)$ of investor heterogeneous sentiment and the interaction term between investor sentiment and the interaction term of dummy variable $\left(S_{t}^{\mathrm{PLS} 2} \cdot D_{t}\right)$.

\section{Empirical Analysis}

4.1. Descriptive Statistics. The initial samples of Shanghai Stock Exchange 180 Index and Shenzhen Stock Exchange 100 Index selected are 249068 and 136786, respectively. This paper excludes 5 types of sample data mentioned in the "Sample selection", as well as the stocks with the weekly return rate of zero, and the final remaining samples are 3750 and 2174 , respectively.

It can be found from Tables 2 and 3 that the standard deviation of investor sentiment is equal to 5.219 whether in the Shanghai or the Shenzhen stock market, indicating that investors have great emotional fluctuations in these two markets. The mean values of $\mathrm{Skew}_{i, t}$ and Duvol ${ }_{i, t}$ are in the range of -0.4 to -0.1 , and the standard deviations are around 0.72 and 0.49 , respectively. It indicates that $\mathrm{Skew}_{i, t}$ and Duvol $_{i, t}$ differ in measuring stock price crash risk. In addition, the variance inflation factor (VIF) of investor sentiment is 1.09 whether in the Shanghai or the Shenzhen stock market. There is no multicollinearity between investor sentiment index and stock price crash risk index in each market. Thus, regression analysis can be taken for further study.

4.2. Regression Analysis. This paper builds a fixed-effect regression model to study the impact of investor sentiment on stock price crash risk in Shanghai and Shenzhen A-share markets. The model is shown in the following expression:

$$
\operatorname{Crashrisk}_{i, t+1}=\alpha+\beta_{1} S_{t}^{\text {PLS2 }}+\sum_{j=2}^{7} \beta_{j} \operatorname{Control}_{i, t}+\varepsilon_{i, t+1} .
$$

In expression (7), Crashrisk ${ }_{i, t+1}$ shows the index of stock price crash risk for $i$-th stock in time $t$, which contains Skew $_{i, t+1}$ and Duvol ${ }_{i, t+1}$. Besides, $S_{t}^{\text {PLS2 }}$ expresses the investor sentiment, and Control $_{i, t+1}$ represents the control variable for $i$-th stock in time $t$.

To further analyze the impact of investor heterogeneous sentiment on stock price crash risk in Shanghai and Shenzhen A-share markets, this paper assumes investor sentiment includes two types: optimistic sentiment and pessimistic sentiment. If $S_{t}^{\mathrm{PL} S 2}$ is greater than its mean value, the investor has optimistic sentiment. Conversely, if $S_{t}^{\text {PLS2 }}$ is less than its mean value, the investor has pessimistic sentiment. The following fixed-effect regression model is constructed, as shown in the following expression:

$$
\begin{aligned}
\text { Crashrisk }_{i, t+1}= & \alpha+\beta_{1} S_{t}^{\mathrm{PLS} 2}+\beta_{2} D_{t}+\beta_{3} S_{t}^{\mathrm{PLS} 2} \cdot D_{t} \\
& +\sum_{j=4}^{9} \beta_{j} \operatorname{Control}_{i, t}+\varepsilon_{i, t+1} .
\end{aligned}
$$

In expression (8), $D_{t}$ is the dummy variable of investor sentiment in time $t$. When an investor has optimistic sentiment, $D_{t}$ equals 1 . Conversely, when an investor has pessimistic sentiment, $D_{t}$ equals 0 . In order to control the possible heteroscedasticity and intragroup autocorrelation, this paper uses expressions (7) and (8) to conduct regression analyses and conducts the clustering robust standard error processing for individual stocks.

4.2.1. Investor Sentiment and the Negative Skewness Coefficient of Weekly Return Rate. In this part, the negative skewness coefficient of weekly return rate (Skew) is taken as the explained variable, and the LSDV method in the fixed effects model is adopted to obtain the regression results of the impact of investor sentiment on stock price crash risk in Shanghai and Shenzhen A-share markets, as shown in Table 4.

The regression results in Table 4 show that the coefficients of investor sentiment $\left(S_{t}^{\text {PLS2 }}\right)$ are significantly positive. From the perspective of holistic sentiment, that is 0.007 and 0.02 in Shanghai and Shenzhen A-share markets, at 5\% and $1 \%$ significant levels, respectively. In the Shanghai A-share market, stock price crash risk increases by $0.7 \%$ for every $1 \%$ increase in investor sentiment. In the Shenzhen A-share market, stock price crash risk increases by $2.5 \%$ for every $1 \%$ increase in investor sentiment. It indicates that investor sentiment can significantly affect stock price crash risk in Shanghai and Shenzhen A-share markets. In other words, 
TABLE 2: Descriptive statistics of the Shanghai Stock Exchange 180 Index.

\begin{tabular}{lccccccccc}
\hline Variable & $S_{t}^{\text {PLS2 }}$ & Skew $_{t+1}$ & Duvol $_{t+1}$ & Ret $_{t}$ & Sigma $_{t}$ & Size $_{t}$ & $P b_{t}$ & Lev $_{t}$ & Roa $_{t}$ \\
\hline Mean & 0.000 & -0.257 & -0.172 & -0.001 & 0.048 & 23.119 & 7.129 & 0.527 & 0.038 \\
Standard deviation & 5.219 & 0.719 & 0.486 & 0.001 & 0.019 & 1.481 & 73.426 & 0.203 & 0.067 \\
Minimum & -5.426 & -3.730 & -2.104 & -0.012 & 0.009 & 18.072 & -2721.501 & 0.030 & -0.979 \\
Maximum & 10.618 & 3.930 & 2.642 & 0.000 & 0.156 & 28.509 & 847.883 & 2.160 & 0.664 \\
\hline
\end{tabular}

Table 3: Descriptive statistics of the Shenzhen Stock Exchange 100 Index.

\begin{tabular}{lccccccccc}
\hline Variable & $S_{t}^{\text {PLS2 }}$ & Skew $_{t+1}$ & Duvol $_{t+1}$ & Ret $_{t}$ & Sigma $_{t}$ & Size $_{t}$ & $P b_{t}$ & Lev $_{t}$ & Roa $_{t}$ \\
\hline Mean & 0.000 & -0.353 & -0.265 & -0.001 & 0.046 & 22.727 & 12.055 & 0.455 & 0.063 \\
Standard deviation & 5.219 & 0.732 & 0.496 & 0.001 & 0.017 & 1.280 & 332.864 & 0.203 & 0.055 \\
Minimum & -5.426 & -3.576 & -2.631 & -0.014 & 0.012 & 15.715 & -18.710 & 0.019 & -0.148 \\
Maximum & 10.618 & 3.709 & 1.746 & 0.000 & 0.159 & 27.784 & 15512.180 & 0.969 & 0.390 \\
\hline
\end{tabular}

TABle 4: The regression results between investor sentiment and the negative skewness coefficient of weekly return rate.

\begin{tabular}{|c|c|c|c|c|}
\hline \multirow{2}{*}{ Skew $_{t+1}$} & \multicolumn{2}{|c|}{ Holistic sentiment } & \multicolumn{2}{|c|}{ Heterogeneous sentiment } \\
\hline & 180-Index & 100-Index & 180-Index & 100-Index \\
\hline C & -0.513 & 1.201 & -0.753 & 1.399 \\
\hline$S_{t}^{\text {PLS2 }}$ & $0.007^{* *}$ & $0.025^{* * *}$ & $0.022^{* *}$ & $0.053^{* * *}$ \\
\hline$D_{t}$ & & & $-0.298^{* * *}$ & $-0.377^{* * *}$ \\
\hline$S_{t}^{\mathrm{PLS} 2} \cdot D_{t}$ & & & 0.016 & 0.007 \\
\hline $\operatorname{Ret}_{t}$ & $135.336^{* * *}$ & $167.842^{* * *}$ & $143.820^{* * *}$ & $191.278^{* * *}$ \\
\hline Sigma $_{t}$ & $9.264^{* * *}$ & $12.327^{* * *}$ & $11.939^{* * *}$ & $16.273^{* * *}$ \\
\hline Size $_{t}$ & 0.005 & $-0.074^{* *}$ & 0.016 & $-0.080^{* *}$ \\
\hline$P b_{t}$ & -0.000 & $0.000^{*}$ & -0.000 & 0.000 \\
\hline $\mathrm{Lev}_{t}$ & 0.088 & -0.278 & 0.066 & $-0.323^{*}$ \\
\hline $\mathrm{Roa}_{t}$ & 0.078 & $2.011^{* * *}$ & 0.039 & $1.825^{* * *}$ \\
\hline$R^{2}$ & 0.172 & 0.200 & 0.184 & 0.216 \\
\hline
\end{tabular}

the rise of investor sentiment in the current period may increase stock price crash risk in the next period. That is because when investor sentiment gradually rises, the stock price will gradually be pushed to a higher level, which will further lead to investor chasing behavior. Finally, the stock price will deviate from the intrinsic value, and as a result, the risk of stock market crash increases. Besides, the regression coefficient is larger in the Shenzhen A-share market rather than the Shanghai A-share market, indicating that investor sentiment has a greater impact on stock price crash risk in the Shenzhen A-share market. That is because the listed companies in the Shanghai A-share market are usually large firms. Also, the system and the mechanism of the Shanghai A-share market are relatively excellent. On the contrary, the listed companies in the Shenzhen A-share market are relatively small, and the ability to resist risks of the listed companies on the SME board market and GEM are weaker. Therefore, from the perspective of holistic sentiment, stock price crash risk in the Shenzhen A-share market is more vulnerable to investor sentiment.

From the perspective of heterogeneous sentiment, the regression coefficients of investor sentiment $\left(S_{t}^{\text {PLS2 }}\right)$ are positive for Shanghai and Shenzhen A-share markets, at 5\% and $1 \%$ significant levels, respectively. Therefore, the conclusion that investor sentiment can significantly affect stock price crash risk in these two markets still holds. Additionally, the coefficient of dummy variable $\left(D_{t}\right)$ is -0.298 and -0.377 at $1 \%$ significant level, respectively. It shows that every $1 \%$ increase in investor pessimism will increase the stock price crash risk in the Shanghai A-share market by $29.8 \%$ and the Shenzhen A-share market by $37.7 \%$. It indicates that investor pessimism has a greater impact on stock price crash risk in the Shenzhen A-share market compared with the Shanghai A-share market. For interaction term of dummy variable $\left(S_{t}^{\text {PLS2 }} \cdot D_{t}\right)$, the regression coefficients are positive, which are not obvious at $5 \%$ significant level. Therefore, it is not concluded that the stock price crash risk increases with the increasing investor optimism. When some investors have pessimistic expectations about stock prices, panic will spread rapidly in the stock market and increase the stock price crash risk. And the appearance of optimistic signals cannot effectively alleviate the pessimism of investors. As a result, with the increase of investor optimism, the stock price crash risk has not changed significantly. Due to the small scale of listed companies in the Shenzhen A-share market, their ability to resist risks is relatively weak. Therefore they are 
more susceptible to market pessimism, leading to a higher stock price crash risk in the Shenzhen A-share market.

4.2.2. Investor Sentiment and the Fluctuation Difference of Stock Price in Different Phases. In this part, the fluctuation difference of stock price in different phases (Duvol) is taken as the explained variable. The LSDV method in the fixed effects model is still adopted to obtain the regression results of the impact of investor sentiment on stock price crash risk in Shanghai and Shenzhen A-share markets, as shown in Table 5 .

The regression results in Table 5 show the coefficients of investor sentiment $\left(S_{t}^{\text {PLS2 }}\right)$ are significantly positive which is consistent with the result above. From the perspective of holistic sentiment, that is 0.004 and 0.019 for Shanghai and Shenzhen A-share markets, at 5\% and 1\% significant levels, respectively. For every $1 \%$ increase in investor sentiment, the stock price crash risk increases by $0.4 \%$ in the Shanghai A-share market and $1.9 \%$ in the Shenzhen A-share market. It turns out that the rising investor sentiment in the current period can increase stock price crash risk in the next period. Also, it has a greater impact on stock price crash risk in the Shenzhen A-share market. Just as the explanation discussed above, sentiment leads to the continuous increase of stock prices and causes the stock price to deviate from the intrinsic value and the rise of stock price crash risk. Considering most of the listed companies in the Shenzhen A-share market are small firms having the weaker ability to resist risk, the stock price crash is more susceptible to investor sentiment in the Shenzhen A-share market from the perspective of holistic sentiment.

From the perspective of heterogeneous sentiment, the regression coefficients of investor sentiment $\left(S_{t}^{\text {PLS2 }}\right)$ are positive at $1 \%$ significant level for Shanghai and Shenzhen A-share markets. The coefficient of dummy variable $\left(D_{t}\right)$ is, respectively, -0.211 and -0.270 at $1 \%$ significant level. It means that every $1 \%$ increase in investor pessimism leads to the increase of stock price crash risk by $21.1 \%$ in the Shanghai A-share market and by $27 \%$ in the Shenzhen A-share market. It indicates that the Shenzhen A-share market is more susceptible to investor sentiment. In addition, the regression coefficients of $S_{t}^{\mathrm{PLS} 2} \cdot D_{t}$ are not significant at 5\% significant level for these two markets. Investor panic caused by pessimistic expectations can increase the stock price crash risk for high-priced stocks. When most of the investors have pessimistic expectations, investor pessimism cannot be changed with the appearance of optimistic signals. Therefore, investor optimism does not significantly affect stock price crash risk. As the scale of listed companies is small, stock price crash risk in the Shenzhen A-share market is more likely to increase with the rising investor pessimism.

The regression results in Tables 4 and 5 show the same conclusions, indicating that Skew and Duvol are consistent in measuring stock price crash risk.

4.2.3. Robustness Test. In order to further alleviate the possible endogeneity problems, this paper adopts the twostage instrumental variable method to perform 2SLS
TABLE 5: The regression results between investor sentiment and the fluctuation difference of stock price in different phases.

\begin{tabular}{|c|c|c|c|c|}
\hline \multirow[t]{2}{*}{$\operatorname{Duvol}_{t+1}$} & \multicolumn{2}{|c|}{ Holistic sentiment } & \multicolumn{2}{|c|}{$\begin{array}{l}\text { Heterogeneous } \\
\text { sentiment }\end{array}$} \\
\hline & 180-Index & 100-Index & 180-Index & 100-Index \\
\hline C & -0.285 & $1.239^{* *}$ & -0.255 & $1.494^{* *}$ \\
\hline$S_{t}^{\text {PLS2 }}$ & $0.004^{* *}$ & $0.019^{* * *}$ & $0.023^{* * *}$ & $0.045^{* * *}$ \\
\hline$D_{t}$ & & & $-0.211^{* * *}$ & $-0.270^{* * *}$ \\
\hline$S_{t}^{\mathrm{PLS} 2} \cdot D_{t}$ & & & -0.001 & -0.003 \\
\hline $\operatorname{Ret}_{t}$ & $82.034^{* * *}$ & $137.051^{* * *}$ & $93.694^{* * *}$ & $156.632^{* * *}$ \\
\hline $\operatorname{Sigma}_{t}$ & $4.714^{* *}$ & $9.371^{* * *}$ & $6.900^{* * *}$ & $12.376^{* * *}$ \\
\hline Size $_{t}$ & 0.004 & $-0.070^{* * *}$ & 0.004 & $-0.078^{* * *}$ \\
\hline $\mathrm{Pb}_{t}$ & 0.000 & $0.000^{* *}$ & 0.000 & 0.000 \\
\hline $\operatorname{Lev}_{t}$ & 0.064 & -0.095 & 0.058 & -0.124 \\
\hline $\mathrm{Roa}_{t}$ & 0.080 & $1.317^{* * *}$ & 0.074 & $1.205^{* * *}$ \\
\hline$R^{2}$ & 0.168 & 0.198 & 0.179 & 0.215 \\
\hline
\end{tabular}

Note. ${ }^{* * *},{ }^{* *}$, and ${ }^{*}$ indicate significant levels at $1 \%, 5 \%$, and $10 \%$, respectively.

regression on the original panel data. The annual average consumer confidence index after excluding the influence of macroeconomy is selected as the instrumental variable. The regression results are shown in Tables 6 and 7 .

The regression results in Tables 6 and 7 show the regression coefficients of investor sentiment $\left(S_{t}^{\mathrm{PLS} 2}\right)$ are positive at $1 \%$ significant level in Shanghai and Shenzhen A-share markets, regardless of whether investor sentiment is optimistic or pessimistic. For the Skew variable, each $1 \%$ increase in investor sentiment leads to a $1.2 \%$ increase in stock price crash risk in the Shanghai A-share market and a 2.2\% increase in stock price crash risk in the Shenzhen A-share market. For the Duvol variable, each $1 \%$ increase in the investor sentiment leads to a $0.7 \%$ increase in stock price crash risk in the Shanghai A-share market and a $1.6 \%$ increase in stock price crash risk in the Shenzhen A-share market. It can be concluded that investor sentiment has a greater impact on the stock price crash risk in the Shenzhen A-share market, because of the smaller size of listed companies in it. As far as investor heterogeneous sentiment is concerned, the regression coefficient of investor sentiment remains positive at $1 \%$ significant level. The coefficients of the dummy variable $\left(D_{t}\right)$ are all negative at $1 \%$ significant level. For the Skew variable, each $1 \%$ increase in investor pessimism leads to a $21.1 \%$ increase in stock price crash risk in the Shanghai A-share market and a 27\% increase in stock price crash risk in the Shenzhen A-share market. For Duvol variable, each $1 \%$ increase in investor sentiment leads to a $29.6 \%$ increase in stock price crash risk in the Shanghai A-share market and a $31.9 \%$ increase in stock price crash risk in the Shenzhen A-share market. It shows that investor pessimism has a significant impact on stock price crash risk, especially in the Shenzhen A-share market. The reason is that listed companies in the Shenzhen A-share market have the weaker ability to resist risk, just as the explanation mentioned above.

The above conclusions are completely consistent with the research conclusions from Tables 4 and 5, indicating that the research conclusions are not changed due to controlling of the endogeneity. Thus, the model constructed in this paper is robust. 
TABLE 6: The regression results involving instrumental variable between investor sentiment and the negative skewness coefficient of weekly return rate.

\begin{tabular}{|c|c|c|c|c|}
\hline \multirow[t]{2}{*}{ Skew $_{t+1}$} & \multicolumn{2}{|c|}{ Holistic sentiment } & \multicolumn{2}{|c|}{$\begin{array}{l}\text { Heterogeneous } \\
\text { sentiment }\end{array}$} \\
\hline & 180-Index & 100-Index & 180-Index & 100-Index \\
\hline C & 0.331 & $-0.980^{* * *}$ & 0.162 & $-1.094^{* * *}$ \\
\hline$S_{t}^{\text {PLS2 }}$ & $0.012^{* * *}$ & $0.022^{* * *}$ & $0.029^{* * *}$ & $0.040^{* * *}$ \\
\hline & & & $-0.296^{* * *}$ & $-0.319^{* * *}$ \\
\hline$S_{t}^{\mathrm{PLS} 2} \cdot D_{t}$ & & & 0.008 & 0.015 \\
\hline $\operatorname{Ret}_{t}$ & $184.954^{* * *}$ & $228.226^{* * *}$ & $187.207^{* * *}$ & $247.913^{* * *}$ \\
\hline $\operatorname{Sigma}_{t}$ & $11.754^{* * *}$ & $15.874^{* * *}$ & $13.540^{* * *}$ & $18.846^{* * *}$ \\
\hline $\mathrm{Size}_{t}$ & $-0.043^{* * *}$ & -0.000 & $-0.034^{* * *}$ & 0.004 \\
\hline$P b_{t}$ & -0.000 & $0.000^{*}$ & -0.000 & 0.000 \\
\hline $\mathrm{Lev}_{t}$ & 0.103 & 0.051 & 0.084 & 0.013 \\
\hline $\operatorname{Roa}_{t}$ & $0.618^{* * *}$ & $2.326^{* * *}$ & $0.623^{* * *}$ & $2.251^{* * *}$ \\
\hline$R^{2}$ & 0.019 & 0.060 & 0.031 & 0.074 \\
\hline$F$-value & $11.49^{* * *}$ & $52.84^{* * *}$ & $13.02^{* * *}$ & $42.68^{* * *}$ \\
\hline
\end{tabular}

TABLE 7: The regression results involving instrumental variable between investor sentiment and the fluctuation difference of stock price in different phases.

\begin{tabular}{|c|c|c|c|c|}
\hline \multirow[t]{2}{*}{ Duvol $_{t+1}$} & \multicolumn{2}{|c|}{ Holistic sentiment } & \multicolumn{2}{|c|}{$\begin{array}{l}\text { Heterogeneous } \\
\text { sentiment }\end{array}$} \\
\hline & 180-Index & 100-Index & 180-Index & 100-Index \\
\hline$C$ & $0.545^{* * *}$ & $-0.571^{* *}$ & $0.472^{* * *}$ & $-0.625^{* * *}$ \\
\hline$S_{t}^{\text {PLS2 }}$ & $0.007^{* * *}$ & $0.016^{* * *}$ & $0.029^{* * *}$ & $0.033^{* * *}$ \\
\hline$D_{t}$ & & & $-0.216^{* * *}$ & $-0.224^{* * *}$ \\
\hline$S_{t}^{\text {PLS2 }} \cdot D_{t}$ & & & -0.007 & 0.005 \\
\hline $\operatorname{Ret}_{t}$ & $106.291^{* * *}$ & $180.962^{* * *}$ & $114.416^{* * *}$ & $197.577^{* * *}$ \\
\hline Sigma $_{t}$ & $6.004^{* * *}$ & $11.806^{* * *}$ & $7.725^{* * *}$ & $14.107^{* * *}$ \\
\hline Size $_{t}$ & $-0.040^{* * *}$ & -0.007 & $-0.035^{* * *}$ & -0.005 \\
\hline$P b_{t}$ & 0.000 & 0.000 & 0.000 & -0.000 \\
\hline $\mathrm{Lev}_{t}$ & 0.069 & 0.061 & 0.061 & 0.040 \\
\hline $\mathrm{Roa}_{t}$ & $0.391^{* *}$ & $1.609^{* * *}$ & $0.407^{* * *}$ & $1.563^{* * *}$ \\
\hline$R^{2}$ & 0.022 & 0.068 & 0.034 & 0.082 \\
\hline$F$-value & $12.90^{* * *}$ & $40.44^{* * *}$ & $14.64^{* * *}$ & $36.26^{* * *}$ \\
\hline
\end{tabular}

Note. ${ }^{* * *},{ }^{* *}$, and ${ }^{*}$ indicate significant levels at $1 \%, 5 \%$, and $10 \%$, respectively.

\section{Conclusions}

This paper adopts the PLS method to construct investor sentiment index in Chinese stock market and studies the impact of investor sentiment on stock price crash risk in Shanghai and Shenzhen A-share markets from two perspectives of holistic sentiment and heterogeneous sentiment. The research conclusions are summarized as follows.

Firstly, investor sentiment can significantly affect stock price crash risk in Shanghai and Shenzhen A-share markets, especially in the Shenzhen A-share market, no matter from which perspective. Specifically, the rising investor sentiment in the current period can increase stock price crash risk in the next period in both stock markets. In the analysis of investment decisions, investor sentiment is easier to interfere with investors' psychological state and leads to decision-making deviation. In this case, the investors may make an excessive reaction in investment behavior. When investor sentiment gradually rises, the stock price is gradually pushed to a higher level, further causing investor chasing. As a result, stock price deviates more and more from its intrinsic value, and stock price crash risk is also increasing.

Secondly, investor pessimism has a greater impact on stock price crash risk in the Shenzhen A-share market from the perspective of heterogeneous sentiment. When some investors in the stock market have pessimistic expectations about future stock prices, the pessimism can spread rapidly in the stock market and increase stock price crash risk. If the stock market is filled with pessimism, the emergence of optimistic signals cannot effectively alleviate investor pessimism. And with the increase of investor optimism, stock price crash risk has not changed significantly.

\section{Data Availability}

The data used to support the findings of this study are available from the corresponding author upon request.

\section{Conflicts of Interest}

The authors declare that they have no conflicts of interest.

\section{Acknowledgments}

The authors would like to thank the National Social Science Fund of China (Grant no. 21XJY014) for the support.

\section{References}

[1] J. Blanchard and M. W. Watson, Bubbles, Rational Expectations and Financial Markets, National Bureau of Economic Research, Cambridge, MA, USA, NBER Working Paper, 1982.

[2] H. Hong and J. C. Stein, "Differences of opinion, short-sales constraints, and market crashes," Review of Financial Studies, vol. 16, no. 4, pp. 487-525, 2003.

[3] D. Zhang and R. Zhang, "Accounting information conservatism, investor heterogeneous belief and stock price crash risk," Research on Financial and Economic Issues, vol. 439, no. 6, pp. 66-74, 2020.

[4] G. Chen and Y. Zhang, "Studies on heterogeneous brief, short sale restriction and the crash phenomenon of stock market in China," Journal of Financial Research, vol. 346, no. 4, pp. 80-91, 2009.

[5] J. Xiong, "Auditor industry specialization and stock price crash risk: evidence form information asymmetry and heterogeneous belief," Journal of Audit \& Economics, vol. 30, no. 6, pp. 47-57, 2015.

[6] G. Franke and E. Lüders, "Instability of financial markets and preference heterogeneity," Advances in Decision Sciences, vol. 2010, Article ID 791025, 28 pages, 2010.

[7] S. Liu, Y. Lee, and Y. Yang, "The systematic crash risk and investor preference in Chinese stock market," Journal of Financial Research, vol. 428, no. 2, pp. 55-70, 2016.

[8] H. Gao, X. Yang, and Y. Ye, "Institutional ownership and extreme price movements: evidence from Chinese markets," 
Journal of Financial Research, vol. 440, no. 2, pp. 163-178, 2017.

[9] J. Dong, J. Pang, X. Li, and Z. Dong, "Exploring the relationship between institutional investor holdings and stock price crash risk: a test based on market variables," Journal of Management Sciences in China, vol. 23, no. 3, pp. 73-88, 2020.

[10] R. J. Shiller, "Gomovements in stock prices and comovements in dividends," The Journal of Finance, vol. 44, no. 7, pp. 719-773, 1989.

[11] J. B. De Long, A. Shleifer, L. H. Summers, and R. J. Waldmann, "Noise trader risk in financial markets," Journal of Political Economy, vol. 98, no. 4, pp. 703-738, 1990.

[12] K. Sun and X. Xiao, "Influence of social media in internet on sentiment contagion and stock price crash," Journal of Technology Economics, vol. 37, no. 6, pp. 93-102, 2018.

[13] B. Shen and X. Chen, "Equity pledge, investor sentiment and stock price collapse risk," Research on Financial and Economic Issues, vol. 2019, no. 9, pp. 72-79, 2019.

[14] L. A. Smales, "The importance of fear: investor sentiment and stock market returns," Applied Economics, vol. 49, no. 34, pp. 3395-3421, 2017.

[15] M. Schmeling, "Investor sentiment and stock returns: some international evidence," Journal of Empirical Finance, vol. 16, no. 3, pp. 394-408, 2009.

[16] H. Li, X. Cheng, and L. Zheng, "A study of investor sentiment impact on the stock price crash risk," Soft Science, vol. 31, no. 7, pp. 98-102, 2017.

[17] M. Li and Z. Li, "Market manipulation and stock price crash risk - influence path analysis based on investor sentiment," Studies of International Finance, vol. 2019, no. 4, pp. 87-96, 2019.

[18] Y. Ge, J. Qiu, Z. Liu, W. Gu, and L. Xu, "Beyond negative and positive: exploring the effects of emotions in social media during the stock market crash," Information Processing \& Management, vol. 57, no. 7, pp. 1-25, 2020.

[19] K. L. Fisher and M. Statman, "Investor sentiment and stock returns," Financial Analysts Journal, vol. 56, no. 2, pp. 16-23, 2000.

[20] G. W. Brown and M. T. Cliff, "Investor sentiment and the near-term stock market," Journal of Empirical Finance, vol. 11, no. 1, pp. 1-27, 2004.

[21] K. Chen and R. Liu, "Studies on the interaction between investor sentiment and stock market," Shanghai Journal of Economics, vol. 2005, no. 11, pp. 86-93, 2005.

[22] L. Qiu and I. Welch, Investor Sentiment Measures, National Bureau of Economic Research, Cambridge, MA, USA, NBER Working Paper, 2006.

[23] M. Baker and J. C. Stein, "Market liquidity as a sentiment indicator," Journal of Financial Markets, vol. 7, no. 3, pp. 271-299, 2004.

[24] L. Han and Y. Wu, "Investor sentiment and IPOs puzzle price suppression or premium," Management World, vol. 23, no. 3, pp. 51-61, 2007.

[25] Q. Chen, M. Zhu, and Q. Lai, "Study on portfolio model based on investor sentiment," Chinese Journal of Management Science, vol. 20, no. 3, pp. 47-56, 2012.

[26] L. F. Ackert, L. Jiang, H. S. Lee, and J. Liu, "Influential investors in online stock forums," International Review of Financial Analysis, vol. 45, no. 5, pp. 39-46, 2016.

[27] M. Baker and J. Wurgler, "Investor sentiment and the crosssection of stock returns," The Journal of Finance, vol. 61, no. 4, pp. 1645-1680, 2006.

[28] Z. Yi and N. Mao, "Research on the measurement of investor sentiment in Chinese stock market: the CICIS's construction,"
Journal of Financial Research, vol. 2009, no. 11, pp. 174-184, 2009.

[29] H.-C. Xu and W.-X. Zhou, "A weekly sentiment index and the cross-section of stock returns," Finance Research Letters, vol. 27, no. 12, pp. 135-139, 2018.

[30] J. Chen, H. Hong, and J. C. Stein, "Forecasting crashes: trading volume, past returns, and conditional skewness in stock prices," Journal of Financial Economics, vol. 61, no. 3, pp. 345-381, 2001.

[31] N. Xu, S. Yu, and Z. Yi, "Institutional investor herding and stock price crash risk," Management World, vol. 29, no. 7, pp. 31-43, 2013.

[32] X. Liu and R. Di, "Heterogeneous institutional investors' shareholding and stock crash risk," Modern Finance and Economics-Journal of Tianjin University of Finance and Economics, vol. 39, no. 7, pp. 3-21, 2019.

[33] A. P. Hutton, A. J. Marcus, and H. Tehranian, "Opaque financial reports, R2, and crash risk," Journal of Financial Economics, vol. 94, no. 1, pp. 67-86, 2009.

[34] Y. Shi and R. Yang, "What has influenced the risk of stock price crashes: tangible information vs. intangible information," Journal of Financial Research, vol. 2018, no. 10, pp. 189-206, 2018.

[35] R. Zhao, X. Xiong, and D. Shen, "Investor sentiment and stock price crash risk: evidence from China," Management Review, vol. 31, no. 3, pp. 50-60, 2019. 